\title{
Axel Ingelman-Sundberg (1910-2009): IUGA loses a founding father
}

\author{
Harold P. Drutz
}

Published online: 27 January 2010

(C) The International Urogynecological Association 2010

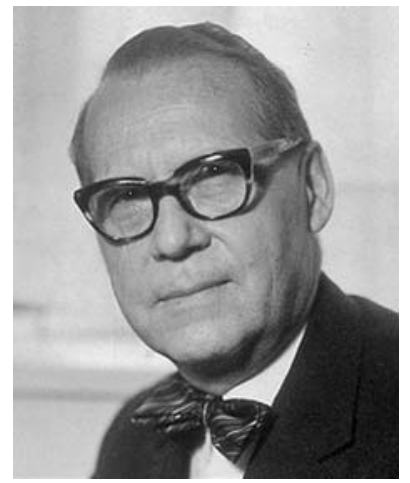

On 12 October 2009, Axel Ingelman-Sundberg passed away after a minor stroke and pneumonia. He was in his 98th year. He leaves behind 6 children and 15 grandchildren.

In 1976, at the Federation International of Gynecology and Obstetrics (FIGO) meeting at Mexico City, Axel and his colleague and friend, Jack Robertson (USA), assembled nine international colleagues-Eckhard Petri (Germany), Oscar Contreras Ortiz (Argentina), Stuart Stanton (UK), Donald Ostergard (USA), David Warrel (UK), Aboo

I would like to thank Kersten Zacharias for helping me with the background information for this tribute to Axel.

\section{H. P. Drutz}

Division of Urogynecology, Department of Obstetrics and Gynecology, Mount Sinai Hospital, University of Toronto, Toronto, ON, Canada

\section{H. P. Drutz $(\square)$}

Joseph and Wolf Lebovic Health Complex,

600 University Avenue,

Toronto, ON M5G 1X5, Canada

e-mail: hdrutz@mtsinai.on.ca

Hassan Abbo (Sudan), Ulf Ulmsten (Sweden), Bozo Kralj (Slovenia), and Wolfgang Fischer (Germany) - to found the International Urogynecological Association (IUGA). IUGA's mission was defined as: "A non-profit international association, dedicated to the advancement of urogynecological knowledge around the world through education and the promotion of basic and clinical research on disorders of the female pelvic floor." Axel was elected as the first president.

Axel was born on 22 December 1910 in Uppsala, Sweden. His father was a clergyman, and his mother, a well-trained doctor. Axel, early on, decided to study medicine and worked in different departments of Uppsala University as an assistant while studying medicine full-time. In 1939, he was ordered to join the army in the war between Finland and Russia, and was transferred to the far north where Sweden borders on Finland. Here, he organized a fully equipped military hospital; he was always a good organizer.

In 1947, he married Mirjam Furuhjelm, MD, a gynecologist who was born in Helsingfors and specialized in gynecological endocrinology. A brilliant lady, she later became an honourary professor. She already had two children, and she and Axel started a large family. She died in May 2003. Among the six children, three are professors in medicine, one is a pathologist, and one daughter is a $\mathrm{PhD}$ in marine archeology, history, and she is also a well-known journalist and writer of historical novels.

Axel was for many years a leading scientist and medical educator as well as a hard-working clinician. His paper, "Intravesical nerve resection for detrusor dyssynergia" (Acta Obstet Gynaecol Scand 38:487, 1959) described partial denervation of the bladder as a new operation for the treatment of urge incontinence. Axel first described the Ingelman-Sundberg technique of repair for stress urinary incontinence using the pubococcygeus muscle. 
This procedure laid the groundwork for Ulf Ulmsten's (a protégé of Axel's) pioneering work on tension-free vaginal tape (TVT), which along with other minimally invasive mid-urethral slings (MIS) has revolutionized the treatment of stress urinary incontinence in women.

Axel, along with his wife Mirjam Furuhjelm, Claes Wirsen, and Lennart Nillson (who was the photographer), published A Child is Born (New York: Delacorte Press, 1966; New York: Dell Publishing, 1969) a textbook that illustrated the nature of life before birth in unprecedented photographs and which served as a practical guide for the expectant mother.

From 1949 to 1979, Axel served as Professor and Head, Department of Obstetrics and Gynecology, Sabbatsberg Sjukhus, Karolinska Institute, Stockholm, Sweden. I had the privilege of working with Axel in the early part of 1975 when I was a McLaughlin Fellow in the burgeoning new field of urogynecology. By that time, Axel was one of the senior gynecologic surgeons in all of Scandinavia. He had become the teacher's teacher, the surgeon's surgeon, and the consultant's consultant. When Axel made his "professor's rounds," his entire department (attending staff, fellows, residents, students, nurses, etc.) were part of his entourage, everyone eager to learn from the master clinician.

For the younger members of IUGA who may not have known Axel personally, you will recall the elderly redhaired gentleman in a jacket and bowtie, who sat in the front row of each scientific session at all the annual clinical meetings (ACM) and whose questions and comments were so erudite and meaningful.

Perhaps the greatest tribute IUGA can pay to Axel is to continue to move forward in the direction the society has taken in becoming the strongest international force in helping women with pelvic floor disorders. 